\title{
Thermal and hydraulic effects on the mechanical behavior of coarse-grained soils used as heat storage media
}

\author{
Henok Hailemariam ${ }^{1, *}$, and Frank Wuttke ${ }^{1}$ \\ ${ }^{1}$ Geomechanics and Geotechnics, Kiel University, Ludewig-Meyn-Straße 10, 24118 Kiel, Germany
}

\begin{abstract}
Assessing the mechanical stability of soils used as heat storage media is vital in the design and wellbeing of sensible heat storage systems, which are typically designed below ground level or as part of the sub-structure of buildings with load bearing capabilities and subjected to frequent water table fluctuations. Nevertheless, considering the importance that moisture and temperature factors have in building a mechanically sound heat storage media, a careful study of such effects has not been given adequate attention in past studies. On this basis, the mechanical performance of two heat storage sandy soils at different moisture contents and temperature conditions is studied in this research. The results show a significant dependence of the mechanical behavior of the investigated soils on moisture content and temperature, which when unaccounted for can result in the inaccurate design of the overall storage system.
\end{abstract}

\section{Introduction}

Closing the gap between energy demand and supply with clean and reliable energy is one of the main challenges of the $21^{\text {st }}$ century. One of the many practical applications of geotechnical engineering in solving the energy problem is via seasonal thermal energy storage systems such as solid sensible heat storage systems (e.g. cemented porous media) or borehole thermal energy storage, BTES, systems (e.g. soils), where heat or cold from solar collectors or other sources of energy is stored for periods of up to several months, for future household and industrial uses (Laing et al. 2006 [1]; Laing et al. 2012 [2]).

Such systems generally have load bearing capabilities and are typically designed as part of the substructure of buildings, and hence accurate assessment of their mechanical stability at all moisture and temperature conditions should be carefully carried out. Furthermore, mechanical failure of the components of the heat storage system, such as formation of cracks, resulting from an inadequate design can have pronounced effects on the efficiency and performance of the overall system. Such failures in the system affect the heat transport to-and-fro the heat storage media via the heat exchanger interface and also within the heat storage medium itself. One parameter which is significantly affected by the formation of cracks within the heat storage media or the BHE is thermal conductivity. The thermal conductivity of the medium controls the rate of charging or discharging of heat storage systems and their overall efficiency (Doughty et al. 1983 [3]; Hart \& Whiddon 1984 [4]).

In view of the aforementioned factors, in this study, the mechanical stability of two heat storage sandy soils at different saturation levels and temperature conditions is assessed experimentally. The research was performed within the framework of project Angus $\mathrm{II}^{\mathrm{a}}$ (Fig. 1), which predominantly aims at developing small and large scale solar powered thermal energy storage systems for domestic and industrial applications. The heat transfer to-and-fro the borehole heat storage soils in the Angus II project is facilitated via cement-based BHEs with a carrier fluid (in this case water). The system provides efficient flexibility in terms of economy, space requirements and operation as compared to other existing heat storage systems. Such thermal energy storage systems are commonly implemented as part of the substructure of buildings or at underground locations near households. Hence assessment of their mechanical performance under the influence of huge loads imposed from the superstructure is necessary.

\section{Experimental program}

\subsection{Tested soils}

Two naturally occurring sandy soils were analyzed: a fine sand, referred to in this study as sand A, S-A (Fig. 2, left), and a coarse sand, referred to in this study as sand B, S-B (Fig. 2, right).

\footnotetext{
a Angus II is a project funded by the German Federal Ministry of Economy and Energy (BMWi), which assesses the impacts of the use of the geological subsurface for thermal, electrical or material energy storage in the context of the transition to renewable energy sources, using the example of SchleswigHolstein, Germany, as a model area
}

\footnotetext{
* Corresponding author: henok.hailemariam@ifg.uni-kiel.de
} 

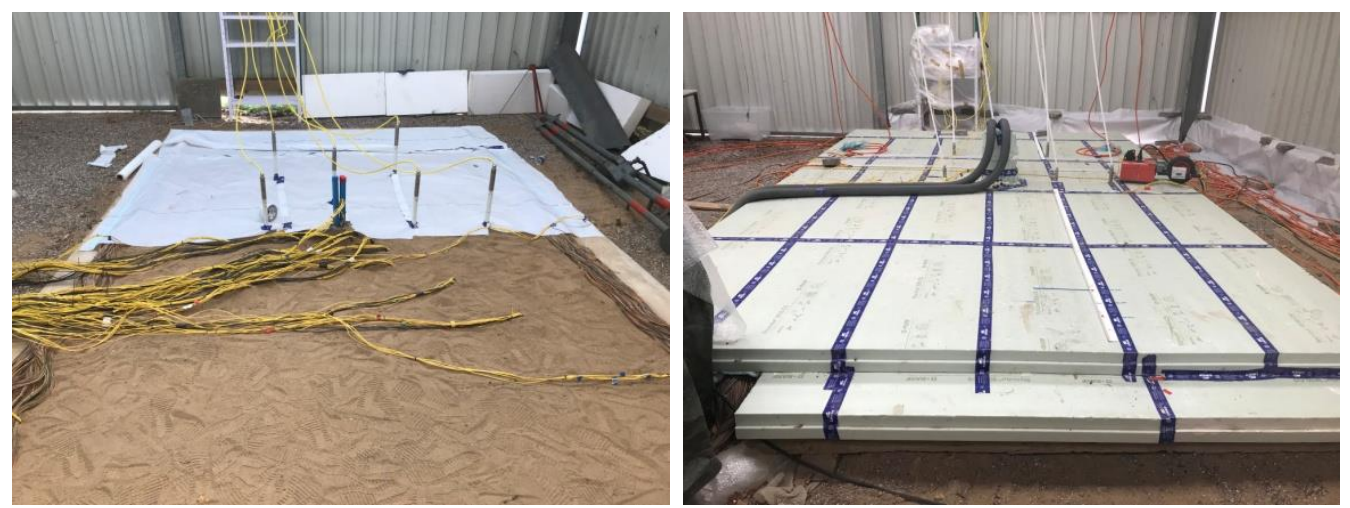

Fig. 1. A meso-scale $5 \times 3 \times 2 \mathrm{~m}^{3}$ experimental indoor high-temperature BTES system of project Angus II in Kiel, Germany (with sand A, Fig. 2, left, as the heat storage material): (left) installation of sensors in the fine sand and (right) the heat storage system after insulation.
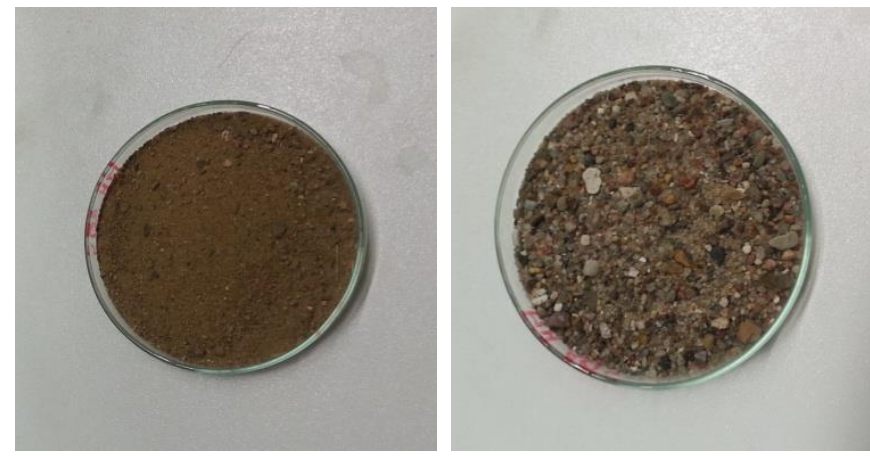

Fig. 2. Samples of: (left) sand A and (right) sand B.

In Table 1, a summary of the obtained physical and geotechnical properties of the soils are presented, and in Figs. 3 and 4, grain size distributions and results of $\mathrm{X}$ ray diffraction (XRD) mineralogical analysis on the two sandy soils are shown, respectively.

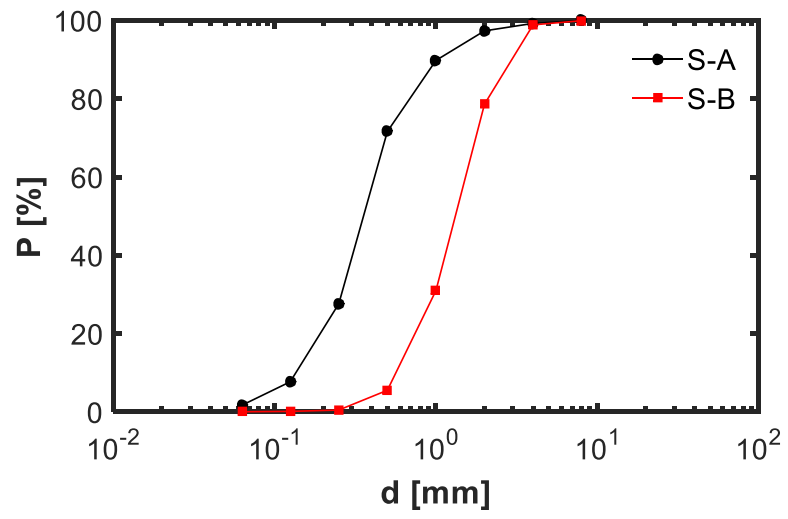

Fig. 3. Grain size distributions (percent passing $P$ vs. grain diameter $d$ ) of the two sandy soils.

\subsection{Equipments used}

In Fig. 5, the one-dimensional compression testing equipments employed to analyze the temperature dependent compressibility of the sandy soils are depicted.
Table 1. Geotechnical properties of the studied sandy soils.

\begin{tabular}{|c|c|c|}
\hline Properties & S-A & S-B \\
\hline Gravel, > 2 mm (wt.\%) & 2.65 & 21.33 \\
\hline Sand, $0.063-2 \mathrm{~mm}$ (wt.\%) & 95.6 & 78.61 \\
\hline Silt and clay, $<0.063 \mathrm{~mm}$ (wt.\%) & 1.75 & 0.06 \\
\hline Porosity $n(-)$ & 0.33 & 0.36 \\
\hline Solids specific gravity $G_{s}(-)$ & 2.68 & 2.67 \\
\hline Bulk dry density $\rho_{d}\left(\mathrm{~kg} \mathrm{~m}^{-3}\right)$ & 1790 & 1700 \\
\hline Grain diameter at $10 \%$ passing $D_{10}(\mathrm{~mm})$ & 0.12 & 0.60 \\
\hline Grain diameter at $50 \%$ passing $D_{50}(\mathrm{~mm})$ & 0.33 & 1.20 \\
\hline Coefficient of uniformity $C_{u}(-)$ & 3.33 & 2.17 \\
\hline Coefficient of curvature $C_{c}(-)$ & 1.30 & 1.28 \\
\hline $\begin{array}{l}\text { Dry effective thermal conductivity } \lambda d r y \\
\left(\mathrm{~W} \mathrm{~m}^{-1} \mathrm{~K}^{-1}\right)^{(1)}\end{array}$ & 0.309 & 0.295 \\
\hline $\begin{array}{l}\text { Saturated effective thermal conductivity } \lambda_{\text {sat }} \\
\qquad\left(\mathrm{W} \mathrm{m}^{-1} \mathrm{~K}^{-1}\right)^{(1)}\end{array}$ & 2.188 & 2.054 \\
\hline $\begin{array}{c}\text { Dry effective specific heat capacity } c_{d r y} \\
\left(\mathrm{M} \mathrm{J} \mathrm{m}^{-3} \mathrm{~K}^{-1}\right)^{(1)}\end{array}$ & 1.355 & 1.269 \\
\hline $\begin{array}{l}\text { Saturated effective specific heat capacity } c_{\text {sat }} \\
\qquad\left(\mathrm{M} \mathrm{J} \mathrm{m}^{-3} \mathrm{~K}^{-1}\right)^{(1)}\end{array}$ & 2.094 & 2.553 \\
\hline $\begin{array}{l}\text { Saturated hydraulic permeability } k_{\text {sat }} \\
\qquad\left(\times 10^{-5} \mathrm{~m} \mathrm{~s}^{-1}\right)\end{array}$ & $0.152^{(2)}$ & 288.0 \\
\hline Unified soil classification system (USCS) & $\mathrm{SP}^{(3)}$ & $\mathrm{SP}^{(3)}$ \\
\hline
\end{tabular}

(1): effective parameters obtained using Decagon KD2 Pro transient thermal needle probes

(2): obtained at an effective stress of $30 \mathrm{kPa}$

(3): SP - poorly graded sand 
Figure 5 (left) shows the set-up with a UL-25 loading machine (with a maximum force limit of $25 \mathrm{kN}$ ) for room temperature testing, and for elevated temperature values an oedometer cell fitted in to a UL-60 loading machine (with a maximum force limit of $60 \mathrm{kN}$ ) with a climate chamber was used as shown in Fig. 5 (right).

To better understand the hydraulic properties of the soils and to supplement the one-dimensional compression tests at varying degrees of saturation of the samples, hydraulic permeability tests under high gradient or pressurized system (Fig. 6, left) for soil A due to its comparatively fine texture, and under low gradient (Fig. 6 , right) for soil $\mathrm{B}$ due to its comparatively coarse texture were performed. The hydraulic conductivity test results are shown in Table 1.

To obtain the water retention behavior of the soils, the water retention curve (WRC) of the soils were obtained using the simplified evaporation method (SEM) (Schindler 1980 [5]; Peters \& Durner 2008 [6]). The WRC, which gives the relationship between water content and matric suction (Williams 1982 [7]; Fredlund \& Rahardjo 1993 [8]), is important in studying the unsaturated behavior of soils. The water content quantifies the amount of water contained within the pores of the porous medium, whereas the matric suction relates to the bonding forces between the porous medium skeleton.

\subsection{Experimental procedure}

The one-dimensional temperature controlled compression tests were performed with oedometer cells which were fitted with a UL-25/60 loading machines and with a climate chamber unit for controlling specimen temperature. The specimens were prepared at a very loose state with a diameter of $70 \mathrm{~mm}$ and a height of 20 mm making sure that the bulk density was homogeneous throughout the specimen volume. The tests were conducted at soil temperatures of 20,40 and $60^{\circ} \mathrm{C}$. Prior to the start of the compression tests, sufficient temperature stabilization time was allotted to achieve steady state conditions within the samples. The effective stress of the specimens was increased from $1 \mathrm{kPa}$ to 400 $\mathrm{kPa}$ at a rate of $4 \mathrm{kPa} / \mathrm{min}$ and then un-loaded back to 1 $\mathrm{kPa}$ at a faster rate of $8 \mathrm{kPa} / \mathrm{min}$, and the specimen deformations were recorded via TRS-0025/TRS-0050 linear transducers with a defined electrical ranges of 25 $\mathrm{mm} / 50 \mathrm{~mm}$, independent linearities of $0.2 \% / 0.15 \%$ and repeatabilities of $2 \mu \mathrm{m}$, respectively. The applied vertical stress and specimen displacement data were monitored and stored with a $\mathrm{PC}$ and a data acquisition unit at a recording interval of around 2 seconds.
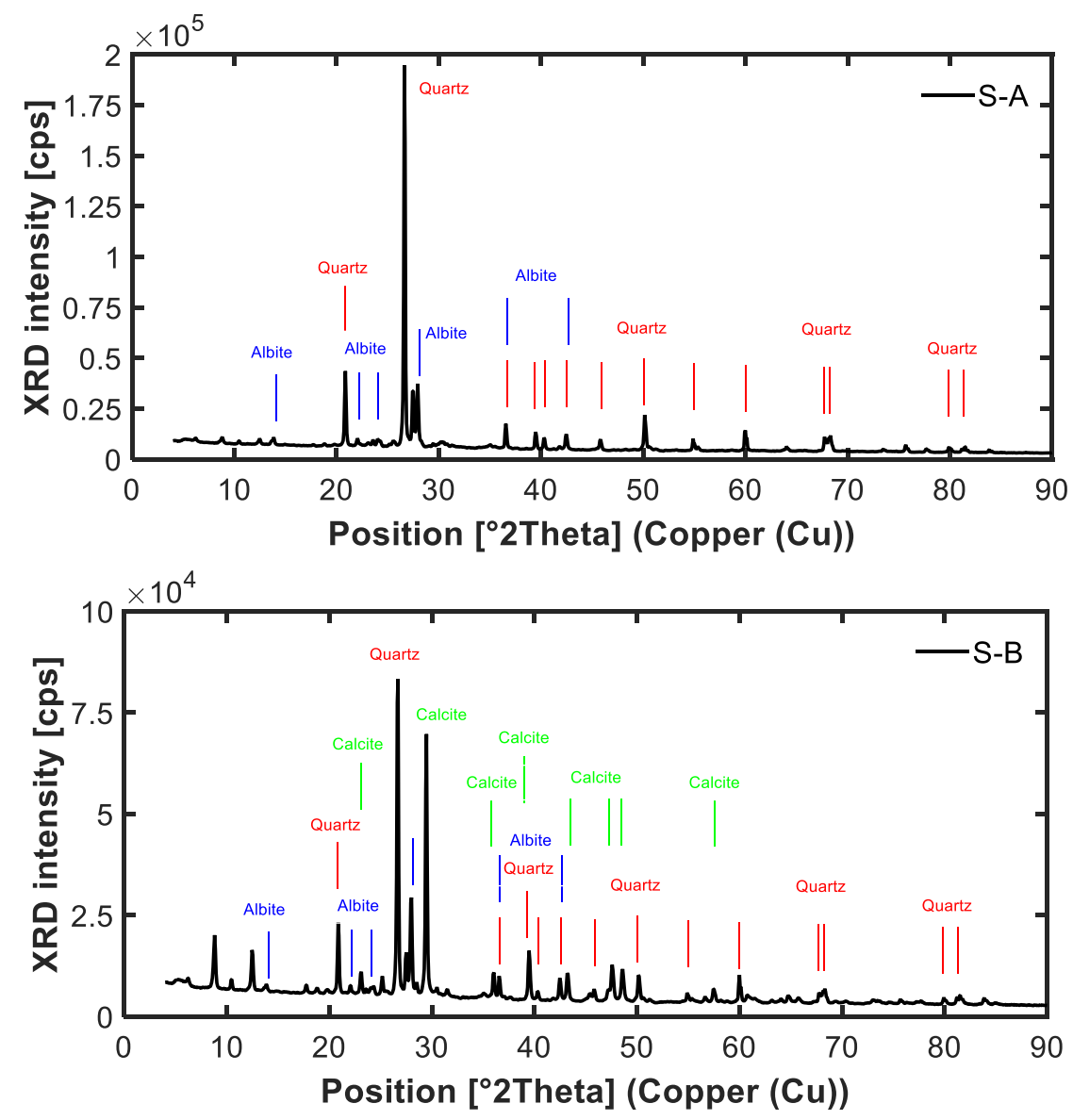

Fig. 4. XRD diagrams of: (top) sand A and (bottom) sand B. 

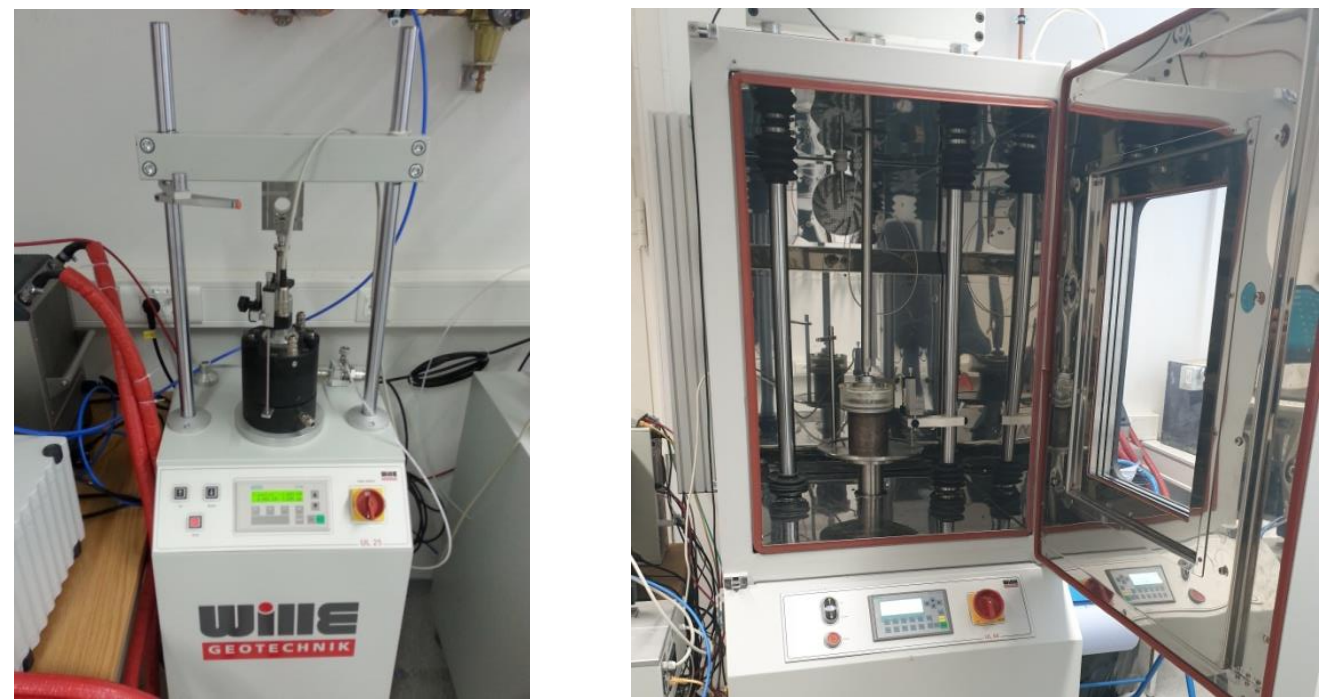

Fig. 5. One-dimensional compression testing equipments used at: (left) room temperature and (right) elevated temperatures.
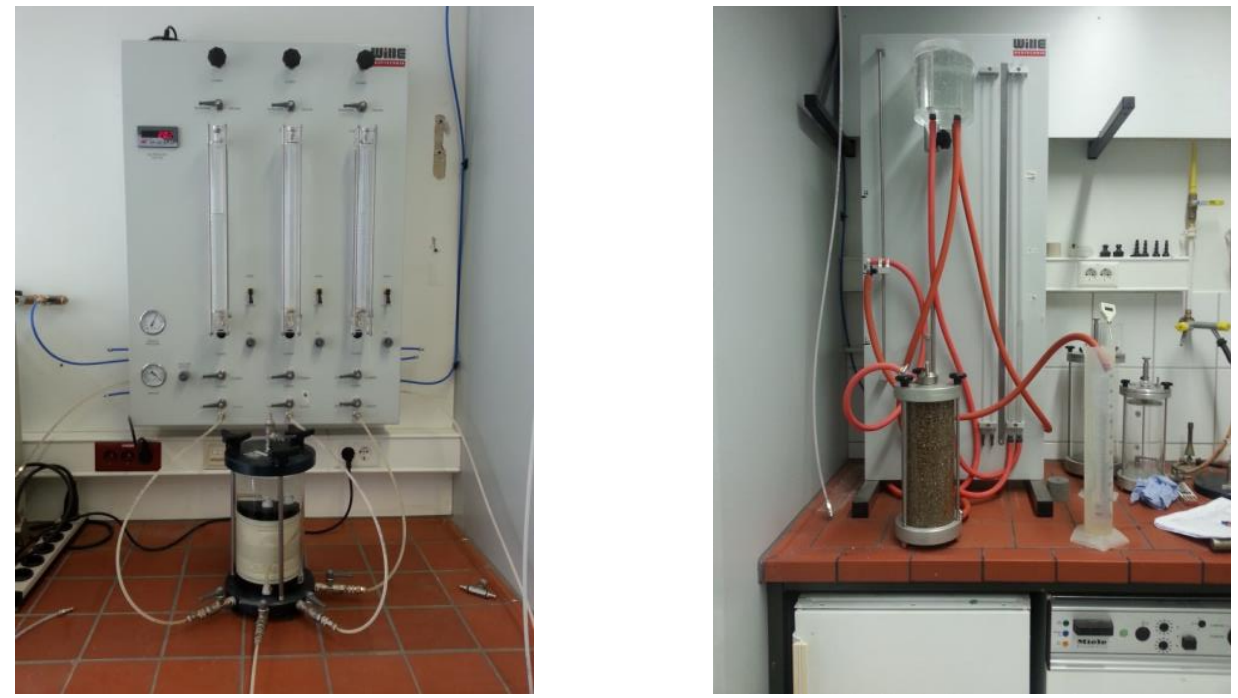

Fig. 6. Hydraulic permeability tests with: (left) high gradient/pressurized system used for sand A and (right) low gradient system used for sand $\mathrm{B}$.

\section{Results and discussion}

In this section, the experimental results of the hydraulic and mechanical behavior tests of the two sandy soils are presented.

\subsection{WRC measurements}

Figure 7 shows the drying path WRCs of the two soils. The tests were repeated on three specimens of each soil. The results show a clear decrease in gravimetric moisture content $w$ of the soils with an increase in matric suction $\left(\psi_{m}=u_{a}-u_{w}\right.$, where $u_{a}$ is the pore-air pressure and $u_{w}$ is the pore-water pressure) following clearly defined zones.

A typical WRC of a porous medium has three zones, namely: saturated, transition and the residual zones (Vanapalli et al. 1996 [9]; Hong et al. 2016 [10]). In the saturated zone (i.e. matric suction lower than the air entry value or AEV, which is the point of intersection of the extensions of the tangent lines in the saturated and transition zones), pore-water does not flow out of the specimen until the matric suction is higher than the intersection point or AEV of the porous medium. In the transition zone, air flows into pores of the porous medium as the matric suction increases, thus forcing the pore-water out of the specimen. The characteristic of the transition zone determines the main slope of the WRC. Once the residual zone is reached, pore-water flow out of the specimen does not occur or is very limited with a further increase in the applied matric suction. This constant state of water content is also called the residual water content of the porous medium.

When comparing the WRCs of the two soils, soil A has a comparatively higher $\mathrm{AEV}$, around $2.10 \mathrm{kPa}$, as compared to that of soil $\mathrm{B}, \mathrm{AEV}$ of around $0.65 \mathrm{kPa}$, due to its relatively smaller pore-sizes, which is also corroborated with its much lower measured hydraulic permeability when compared to that of soil B (Table 1). 
Soil A due to its smaller pore-size and comparatively lower hydraulic permeability requires a higher suction potential to drive moisture out of its pores during the drying or desorption process, and hence has a higher AEV than soil B.
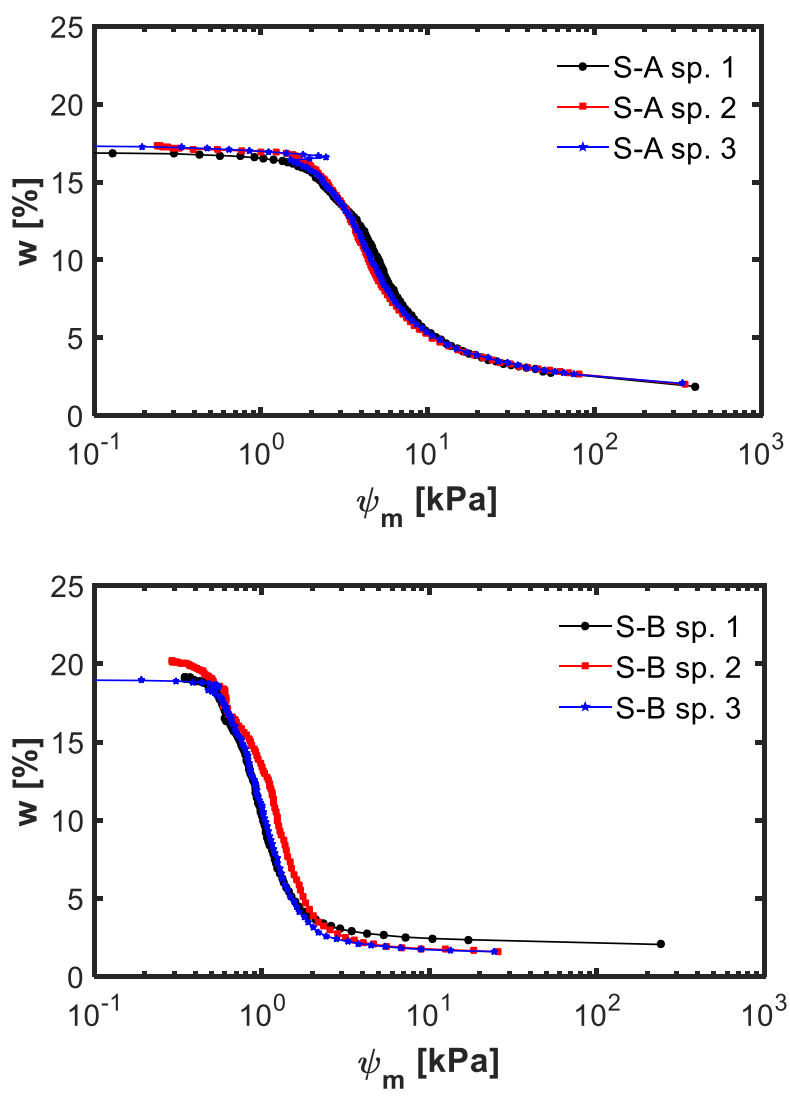

Fig. 7. WRCs of the sandy soils: (top) sand A and (bottom) sand $B$.

\subsection{Moisture content dependent oedometric tests}

In Fig. 8, results of the one dimensional compression tests on the soils at dry and fully saturated moisture conditions are presented. The tests were performed under room temperature conditions, which varied in the range between 19.2 and $20.7^{\circ} \mathrm{C}$. The stresses mentioned in this study are all effective stresses, even though the exact pore-water pressures were not measured especially for the tests performed at fully saturated conditions. This is justified as the rate of loading used in this study is slow enough in view of the hydraulic properties of the soils, so as not to cause the generation of excess pore-water pressures in the samples. Hence, the total and effective stresses acting on the soils can be assumed to be equal.

The results show a general increase in the compressibility of both soils with increase in moisture content. At dry condition (equivalent to high soil matric suction), interlocking and friction between the quartz, albite and calcite dominated soil grains is at its highest and hence the resistance to deformation is maximum.

Whereas, at saturated conditions (equivalent to low soil matric suction) or when the moisture content of the soil is increased, the soil grains are lubricated, resulting in the lowering of the frictional forces between the grains and their interlocking, producing higher deformations upon the application of stress. When comparing the recorded vertical strains of each soil, sand A has a comparatively higher deformation for the given stresses at both moisture conditions, mainly due to its relatively finer-grain size or texture as compared to that of sand B.
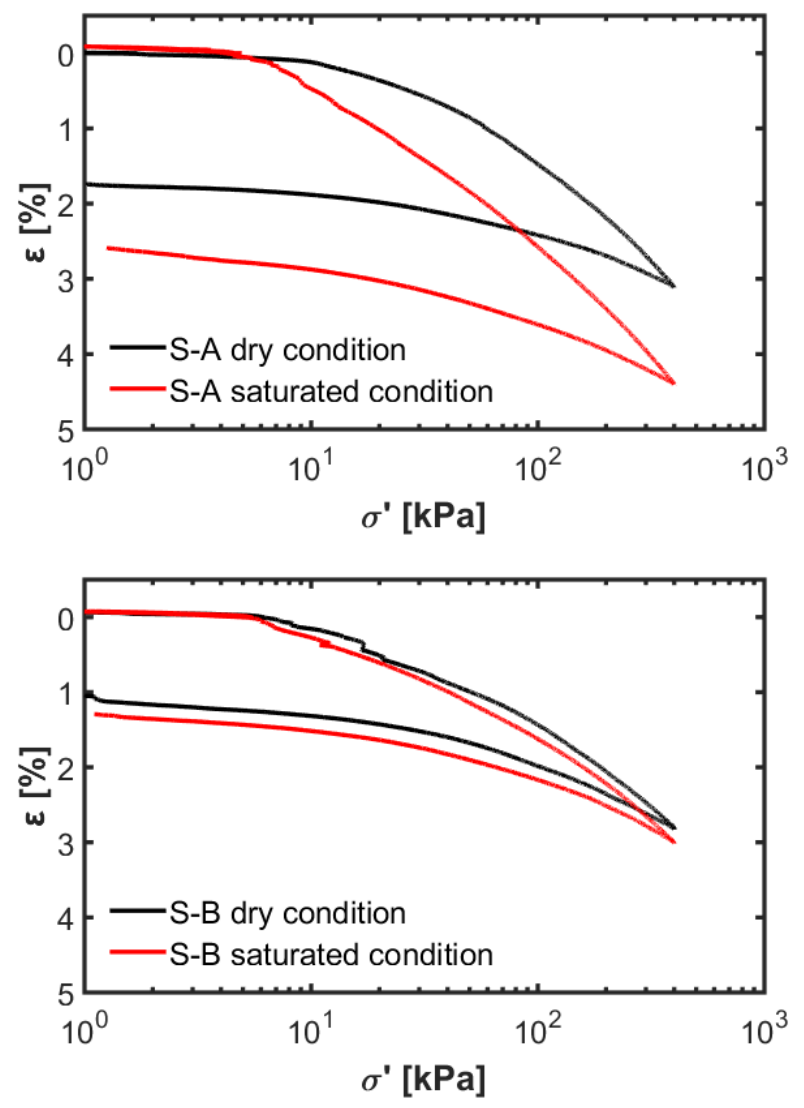

Fig. 8. One dimensional compression test results at room temperature and at different levels of saturation for: (top) sand A and (bottom) sand B.

\subsection{Temperature dependent oedometric tests}

Figure 9 depicts the results of the one dimensional compression tests on the heat storage soils at different medium temperatures. The temperature dependent tests were all performed at dry soil conditions.

The results show that the compressibility of both soils decreases with an increase in the medium temperature. For soils which are initially in a loose state, an increase in temperature results in the re-arrangement of the mineral soil grains and soil skeleton producing a thermal contractive behavior prior to the application of the vertical stress, resulting in a more compact and denser medium with an increased stiffness, thus producing a more stable and less compressible medium. These findings are in agreement with previous findings (Burghignoli et al. 2000 [11]), where dense and overconsolidated soils show a thermal dilatant behavior after heating at elevated temperatures, thereby loosing 
strength, and where by contrast loose and normally consolidated soils show a thermal contractive behavior after heating, thereby gaining strength.

A more pronounced effect of this can also be seen for soils which are subjected to either a mechanical (Sawicki \& Swidzinski 1989 [12]; Duku et al. 2008 [13]) or a thermal $(\mathrm{Ng}$ et al. 2016 [14]; Vega \& McCartney 2015 [15]) cyclic loading, where after several cycles of mechanical loading or heating and cooling processes, the soils typically exhibit a compaction due to the accumulation of plastic mechanical or thermal strains, during processes which are typically known as mechanical compaction or thermal consolidation, respectively. This compaction then generally results in the increased resistance to compressibility of the soils.

The outcome of the study suggests that an increase in the temperature of the sandy soils which are used as medium of heat storage, does not have a direct negative impact on the mechanical stability or load bearing capacity of the soils. However, extra or induced stresses generated in the heat storage system, which might arise due to the unequal thermal expansion of the various components of the system, can undermine the overall safety of the heat storage system, and hence should be checked prior to the design and operation procedures.
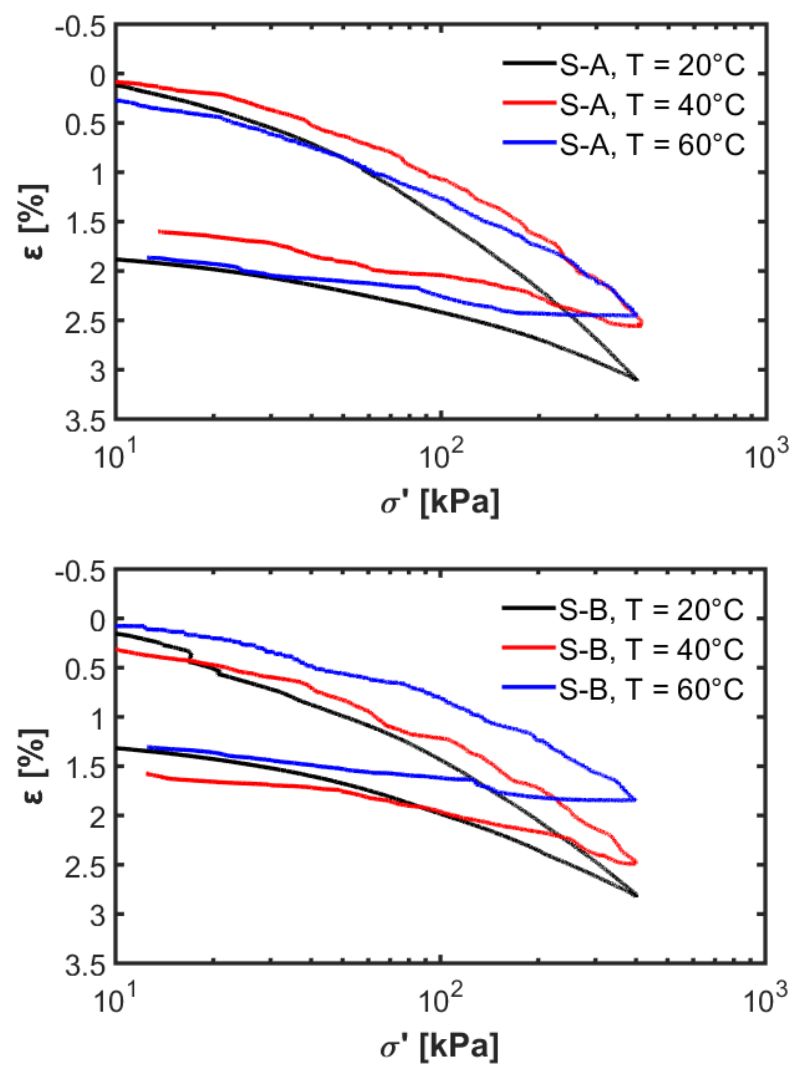

Fig. 9. One dimensional compression test results at dry soil conditions and different temperatures for: (top) sand A and (bottom) sand B.

\section{Conclusions}

Moisture and temperature changes affect the mechanical behavior of soils and can play an essential role in the planning and design of most solid sensible and borehole thermal energy storage systems, which are usually designed at or below ground level, with load bearing capabilities and where fluctuations in the levels of the water table are frequent. On this regard, the mechanical performance of two sandy soils (used as heat storage media) at different moisture contents and temperature conditions was studied in this research. An increase in moisture content of the soils produced a reduction in stiffness, which was seen as an increase in the recorded strain for the given stresses, mainly due to the lubricating effect of water on the soil grains and a subsequent reduction in inter-granular friction.

Whereas, an increase in medium temperature, resulted in a stiffer soil mass, mainly due to rearrangement of the quartz and albite dominated soil grains and better particle-to-particle inter-locking, which resulted after the heating process. Overall, the results show a significant dependence of the mechanical behavior of the investigated materials on moisture content and temperature, which when unaccounted for can result in the inaccurate design of the overall heat storage system.

\section{Acknowledgements}

The authors would like to acknowledge the financial support provided by the German Federal Ministry for Economic Affairs and Energy (BMWi) under the Grant number 03ET6122A (Project ANGUS II) as well as the support of Project Management Jülich. We thank Paul Liedtke, formerly of Geohydromodellierung Group, Kiel University, for kindly providing us with the field test images shown in Figure 1, and Kerstin Meier zu Beerentrup, Angewandte Geologie Group, Kiel University, for her support in analyzing the XRD measurements of the soils. We are also grateful to the Department of Soil Science and Soil Physics of Technische Universität Braunschweig, Germany, for performing the SEM measurements.

\section{References}

1. D. Laing, W-D. Steinmann, R. Tamme, C. Richter. (2006). Solid media thermal storage for parabolic trough power plants. Solar Energy 80:10, 12831289

2. D. Laing, C. Bahl, T. Bauer, M. Fiss, N. Breidenbach, M. Hempel. (2012). High-temperature solid-media thermal energy storage for solar thermal power plants. Proceedings of the IEEE 100:2, 516524

3. C. Doughty, A. Nir, C.F. Tsang, G.S. Bodvarsson. (1983). Heat storage in unsaturated soils: Initial theoretical analysis of storage design and operational method. Proceedings of the International Conference on Subsurface Heat Storage in Theory and Practice, Stockholm 
4. G.K. Hart \& W.I. Whiddon. (1984). Ground source heat pump planning workshop. Summary of Proceedings, Palo Alto: Electric Power Research Institute, EPRI Report RP 2033-12

5. U. Schindler. (1980). Ein Schnellverfahren zur Messung der Wasserleitfähigkeit im teilgesättigten Boden an Stechzylinderproben. Archiv für Ackerund Pflanzenbau Bodenkunde 24:1, 1-7

6. A. Peters \& W. Durner. (2008). Simplified evaporation method for determining soil hydraulic properties. Journal of Hydrology 356, 147-162

7. P.J. Williams. (1982). The surface of the earth: An introduction to geotechnical science (AddisonWesley Longman Ltd, New York, USA)

8. D.G. Fredlund \& H. Rahardjo. (1993). Soil mechanics for unsaturated soils (John Wiley \& Sons Inc., New York, USA)

9. S.K. Vanapalli, D.G. Fredlund, D.E. Pufahl, A.W. Clifton. (1996). Model for the prediction of shear strength with respect to soil suction. Can. Geotech. J. 33, 379-392

10. W-T. Hong, Y-S. Jung, S. Kang, J-S. Lee. (2016). Estimation of soil-water characteristic curves in multiple-cycles using membrane and TDR system. Materials 9, 1019

11. A. Burghignoli, A. Desideri, S. Miliziano. (2000). A laboratory study on the thermomechanical behaviour of clayey soils. Can. Geotech. J. 37, 764780

12. A. Sawicki \& W. Swidzinski. (1989). Mechanics of a sandy soil subjected to cyclic loadings. Int. J. Numer. Anal. Methods Geomech. 13, 511-529

13. P.M. Duku, J.P. Stewart, D.H. Whang, E. Yee. (2008). Volumetric strains of clean sands subject to cyclic loads. J. Geotech. Geoenviron. Eng. ASCE 134, 1073-1085

14. C.W.W. Ng, S.H. Wang, C. Zhou. (2016). Volume change behaviour of saturated sand under thermal cycles. Géotechnique Letters 6, 124-131

15. A. Vega \& J.S. McCartney. (2015). Cyclic heating effects on thermal volume change of silt. Environmental Geotechnics 2, 257-268 